\title{
Evaluation of Real-Time Water Quality Sensors for the Detection of Intentional Bacterial Spore Contamination of Potable Water
}

Samendra P Sherchan ${ }^{1,2 *}$, Charles P Gerba1 and lan L Pepper ${ }^{2}$

${ }^{1}$ Department of Soil, Water, and Environmental Science, University of Arizona, Tucson, Arizona, USA

${ }^{2}$ Environmental Research Laboratory, University of Arizona, Tucson, Arizona, USA

\begin{abstract}
Water utility treatment failure, as well as intentional or accidental water intrusions can introduce biological and/ or chemical contaminants into public drinking water distribution systems. However, recently developed real-time water quality sensors can be implemented to detect such contamination events. The overall objective of this study was to evaluate the potential for real-time monitoring of bacterial spore contamination of potable water using several different water quality sensors including: the $\mathrm{HACH}$ Monitoring Platform; the JMAR BioSentry unit; and the S::CAN spectro::Iyser technology. For this, Bacillus thuringiensis spores were used as a surrogate for Bacillus anthracis. The minimum threshold response of sensors to the microbial contaminant was determined by injecting $B$. thuringiensis spores into Deionized (DI), filtered or unfiltered tap water. Out of these three evaluated sensors, the BioSentry sensor was capable of detecting introduced spores and responded to $B$. thuringiensis spores over a concentration range of $10^{2}-10^{5}$ spores $/ \mathrm{ml}$. In contrast, The $\mathrm{HACH}$ and S::CAN units were not capable of direct detection of spores. However, these two sensors can detect changes in water quality parameters such as turbidity, $\mathrm{pH}$, temperature, total organic carbon and conductivity, due to media that may be associated with spores. Thus, these sensors can be integrated into a contaminant warning system for monitoring intrusion events in water distribution systems.
\end{abstract}

Keywords: Online monitoring; Water quality sensors; Bacillus spore; Real-time detection

\section{Introduction}

Access to high quality water through sustainable treatment and effective water distribution systems is essential to contemporary life in developed countries. To monitor for microbial contaminants most municipal water utilities rely on indicator organism tests (i.e. fecal coliform or E. coli tests) that take up to 24 hours to obtain results, and are incapable of monitoring pathogens need to be detected in real-time. As a consequence, distribution systems are relatively unprotected and vulnerable to intentional, natural, or accidental contamination from microbial agents [1]. The lack of real-time monitoring of distribution systems potentially exposes the public to pathogenic microorganisms.

The use of integrated and intelligent sensors to operate in real-time, with the ability to recognize and diagnose day-to-day and perhaps minute-to-minute water quality disturbances can monitor water quality through the detection of intentional or operational intrusion events, thus improving water security. When contamination events are recognized in real-time, a rapid response can minimize the impact of these contamination events and limit the potential for adverse effects [2].

The objective of this study was to evaluate the potential for realtime monitoring of $B$. thuringiensis spores as a surrogate for $B$. anthracis using a variety of water quality sensors.

\section{Experimental Methods}

At the University of Arizona Real-time sensor Lab, water is delivered by the City of Tucson Water public utility. In this study, Deionized (DI) water as a control or prefiltered tap water using $1 \mu \mathrm{m}$ pore size filter was utilized as the water source.

Sensors evaluated in experiments were:

\section{HACH Monitoring Platforms: Non-Specific Sensors}

(HACH, PO Box 389, Loveland, CO 80539)
This multi-parameter unit utilizes in-line sensors. The measured parameters include: $\mathrm{pH}$, Total Organic Carbon (TOC), free chlorine, turbidity, electrical conductivity, pressure, and temperature. TOC is measured with a Non-Dispersive Infrared (NDIR) method by adding $0.6 \mathrm{M}$ phosphoric acid and $0.6 \mathrm{M}$ sodium per sulfate to the water sample to produce TOC. Subsequently, the TOC is oxidized by UV light to make $\mathrm{CO}_{2}$ and this gas/liquid mixture is separated and the gas read by an NDIR detector. The output is directly proportional to the original TOC in the sample.

\section{BioSentry $^{\mathrm{TM}}$ Technology: Light Scattering}

(JMAR, 10905 Technology Place, San Diego, CA 92127).

The BioSentry is an in-line sensor that allows for continuous realtime monitoring of particulates by using Multi-Angle Light Scattering (MALS) technology. The sensor contains a laser beam that strikes individual cells or particles in water, resulting in unique light scattering patterns. Such patterns depend on the size and morphological characteristics of the target particle. Data obtained are compared to a computerized database of patterns from different kinds of microbes, which are then placed into four identifiable categories: rods, spores, protozoa, and unknown (applied for particles of an appropriate size for the prior categories but not classified specifically as being a member of the three categories). The data output is shown in counts/minute for each category, and can be converted to organisms $/ \mathrm{ml}$ allowing

*Corresponding author: Sherchan, Environmental Research Lab, University of Arizona, Tucson, Arizona, USA, Tel: 1-319-400-9564; Fax: 1-520-573-0852; E-mail: samendrasherchan@email.arizona.edu

Received July 19, 2013; Accepted September 11, 2013; Published September 19,2013

Citation: Sherchan SP, Gerba CP, Pepper IL (2013) Evaluation of Real-Time Water Quality Sensors for the Detection of Intentional Bacterial Spore Contamination of Potable Water. J Biosens Bioelectron 4: 141. doi:10.4172/2155-6210.1000141

Copyright: (c) 2013 Sherchan SP, et al. This is an open-access article distributed under the terms of the Creative Commons Attribution License, which permits unrestricted use, distribution, and reproduction in any medium, provided the original author and source are credited. 
comparison with standard microbial assays such as colony forming units/ml or spores/ml.

\section{S::CAN spectro::lyser Technology: Light Scattering}

(S::CAN Measuring Systems LLC, PO Box 36402, Cincinnati, OH 45236).

The S::CAN is a multi-parameter sensor that uses UV-Visible spectroscopy to generate a broadband picture of overall water quality. Any introduced contaminant in the water is detected as a deviation from the baseline or reference signal. The reference signal is normally generated from water samples that allow for the system to be trained to a standard composition. This is essential for real-time monitoring to reduce the incidence of false alarms. The sensor produces spectral data between 200 and $700 \mathrm{~nm}$ referenced to pre-set algorithms for several water quality parameters and alarms triggers. Output measurements from the S::CAN analyzed for this study include turbidity, Dissolved Organic Carbon (DOC) and Total Organic Carbon (TOC).

\section{Experimental design}

For all experiments a baseline output from all sensors was established for 30-60 minutes by passage of either DI or tap water. Subsequently, sensors were challenged with $B$. thuringiensis (ATCC, \#10792) as the bacterial surrogate for Bacillus anthracis to evaluate the response of a microbial intrusion. B. thuringiensis was cultured in 2XSG sporulation media [3]. The sporulation medium contained $16 \mathrm{~g}$ Difco nutrient broth, $17 \mathrm{~g}$ agar, $2 \mathrm{~g} \mathrm{KCl}, 0.5 \mathrm{~g} \mathrm{MgSO}_{4}, 1 \mathrm{ml} 1 \mathrm{M} \mathrm{Ca}\left(\mathrm{NO}_{3}\right)_{2}, 1$ $\mathrm{ml} 0.1 \mathrm{M} \mathrm{MnCl}_{2} .4 \mathrm{H}_{2} \mathrm{O}, 1 \mathrm{ml} 1 \mathrm{M} \mathrm{FeSO}_{4} \cdot 4 \mathrm{H}_{2} \mathrm{O}$ and $0.5 \%$ glucose $(\mathrm{pH}$ 7.0). After incubation at $37^{\circ} \mathrm{C}$ for one week, spores were suspended into sterile deionized water, washed three times centrifuged at $2,400 \times \mathrm{g}$ for 30 minutes, and when sufficiently clean ( $>90 \%$ spores), were examined with a Petroff Hausser counting chamber (model 3900; Hausser Scientific, Horsham, PA). Confirmation of the inactivation of vegetative cells was confirmed by plating dilutions of preparations in duplicates after heating at $80^{\circ} \mathrm{C}$ for 10 minutes. The experiments used $B$. thuringiensis spores suspended in cold sterile distilled water. The $B$. thuringiensis suspension was diluted into a $50 \mathrm{~L}$ carboy containing $45 \mathrm{~L}$ of water to achieve final spore concentrations of $10^{2}, 10^{3}, 10^{4}$ or $10^{5}$ spores $/ \mathrm{ml}$. The $45 \mathrm{~L}$ water sample was mixed with a water pump for five minutes prior to the start of each experiment. Water samples were pumped into inline sensors that were arranged in parallel so that each sensor contacted the same contaminated water at essentially the same time. During the injection, the pressure and temperature remained constant with a water flow rate of $1.2 \mathrm{~L} / \mathrm{min}$ for 30 minutes to create a steady state injection. Fifteen milliliter water samples were obtained at sampling point \#1 during the 10, 15, 20, 25, and 30 minutes time points (Figure 1). Spores were enumerated with a Petroff Hausser $(\mathrm{PH})$ counting chamber, and also by cultural plating to assess consistency between spore preparation and viability. In addition, control experiments were also conducted in water not receiving spores. The values used in the analysis of the data were an average of the values at the peak of the injection. Normalized values were calculated as follows:

$$
\Delta \mathrm{I}=\left(\mathrm{I}-\mathrm{I}_{\mathrm{o}}\right) / \mathrm{I}_{\mathrm{o}}
$$

Where:

\section{$\mathrm{I}=$ Average signal value at peak.}

$I_{0}=$ Baseline signal value at the beginning of experiment.

To determine how the BioSentry reacts to a mixture of vegetative

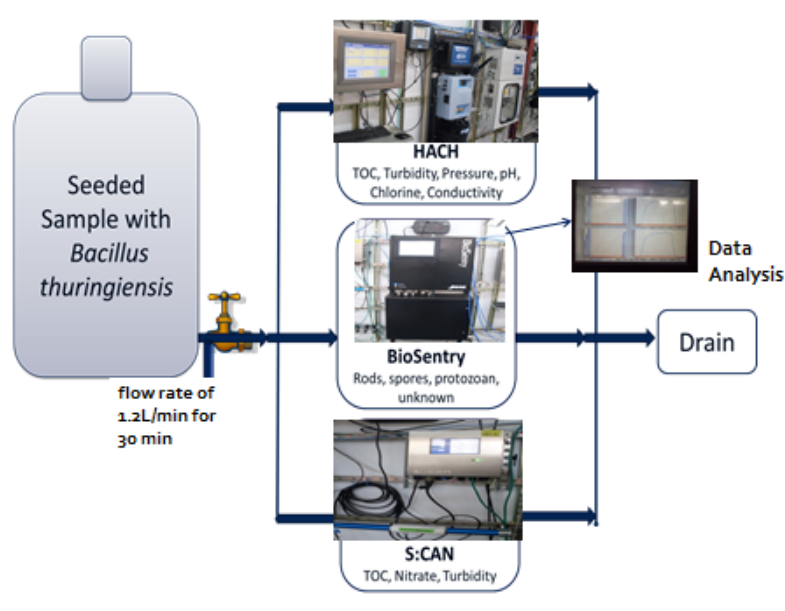

Figure 1: Schematic of Experimental-set-up at the Real-Time Sensor Lab.

cells and spores, $1.1 \times 10^{6} \mathrm{cfu} / \mathrm{ml}$ of $E$. coli and $8.4 \times 10^{5}$ spores $/ \mathrm{ml}$ of $B$. thuringiensis were both added to $45 \mathrm{~L}$ of DI water and injected into a distribution system. E. coli (ATCC, \#15597) was grown in Tryptic Soy Broth (TSB) (BD, Sparks, MD) to late log phase. Samples were obtained as previously described and were subsequently diluted and plated on Tryptic Soy Agar (TSA) (Neogen, Lansing, MI) to determine E. coli concentrations. The plates were incubated for $24 \mathrm{hr}$, and colonies were counted to confirm the bacterial concentration in the water samples. In addition, the samples were also stained with acridine orange to obtain a direct count (AODC) of E. coli cells. In contrast, B. thuringiensis spores were enumerated as described previously.

\section{Results and Discussion}

The objective of this study was to evaluate the ability of commercial sensors to detect $B$. thuringiensis bacterial spores in-line and in real-time. To this end, three sensors were all evaluated in parallel. Experiments were performed by inoculating DI and tap water with B. thuringiensis at concentrations over a range of $10^{2}-10^{5}$ spores $/ \mathrm{ml}$, and injecting this water into a field scale test-bed distribution system for 30 minutes in a single-pass mode at $1.2 \mathrm{~L} / \mathrm{min}$. The BioSentry was successful in recognizing the pulse of spores coming through the carboy in the intermediate-scale testing water distribution system laboratory (Tables 1-3). None of the other sensors showed significant consistent responses from the baseline values (HACH, S::CAN). The numerical value of the BioSentry output for spore counts correlated well with the actual input spore concentration with an $R^{2}$ value 0.93 in DI water. Corresponding correlations for $B$. thuringiensis in filtered and unfiltered were $\mathrm{R}^{2}=0.87$ and $\mathrm{R}^{2}=0.88$, respectively. Overall, similar high correlations were also seen in a USEPA study [4] (2010). However, the maximum concentration used in the EPA study was $2.5 \times 10^{4}$ spores $/ \mathrm{ml}$, and the B. globigii concentrations were compared only to the unknown category output from the BioSentry. Despite this, the study exhibited an $\mathrm{R}^{2}$ value of 0.99 [4]. In addition, all the BioSentry responses to spore inputs were significantly different from baseline values.

When examining each concentration individually, the BioSentry output for $B$. thuringiensis injections quantitatively coincided with the absolute counts from the Petroff Hausser and cultural plating with few exceptions (Figures 2-4). The BioSentry spore equivalent was significantly lower than the cultural and Petroff Hausser method when Bacillus thuringiensis was introduced into DI water at a concentration of 
Citation: Sherchan SP, Gerba CP, Pepper IL (2013) Evaluation of Real-Time Water Quality Sensors for the Detection of Intentional Bacterial Spore Contamination of Potable Water. J Biosens Bioelectron 4: 141. doi:10.4172/2155-6210.1000141

Page 3 of 5

\begin{tabular}{|c|c|c|c|c|c|c|c|}
\hline $\begin{array}{l}\text { Final Spore Concentration } \\
\text { (spores/ml) }\end{array}$ & $\begin{array}{l}\text { BioSentry } \\
\text { (spores } / \mathrm{ml} \text { ) }\end{array}$ & $\begin{array}{l}\text { HACH Turbidity } \\
\text { (NTU) }\end{array}$ & HACH TOC (mg/L) & $\begin{array}{l}\text { HACH Chlorine } \\
\text { (mg/L) }\end{array}$ & $\begin{array}{l}\text { S::CAN Turbidity } \\
\text { (FTU) eq }\end{array}$ & $\begin{array}{l}\text { S::CAN DOC } \\
(\mathrm{mg} / \mathrm{L}) \text { eq }\end{array}$ & $\begin{array}{l}\text { S::CAN TOC } \\
\text { (mg/L) eq }\end{array}$ \\
\hline \multirow[t]{2}{*}{$1.0 \mathrm{E}+02$} & $3.3+\mathrm{E} 03 \pm 2.6+\mathrm{E} 03$ & $0.18 \pm 0.19$ & $0.62 \pm 0.11$ & $0.06 \pm 0.03$ & $0.16 \pm 0.02$ & $0.25 \pm 0.03$ & $0.86 \pm 0.05$ \\
\hline & 1.1 & -0.84 & -0.56 & -0.07 & -0.06 & 0.04 & 0.30 \\
\hline \multirow[t]{2}{*}{$1.0 \mathrm{E}+03$} & $2.6+\mathrm{E} 04 \pm 1.1+\mathrm{E} 04$ & $0.31 \pm 0.14$ & $0.18 \pm 0.01$ & $0.04 \pm 0.01$ & $0.19 \pm 0.01$ & $0.32 \pm 0.05$ & $0.4 \pm 0.07$ \\
\hline & 5.5 & -0.61 & 0.02 & -0.93 & -0.15 & 0.17 & 0.08 \\
\hline \multirow[t]{2}{*}{$1.0 \mathrm{E}+04$} & $3.5+\mathrm{E} 04 \pm 2.8+\mathrm{E} 04$ & $0.3 \pm 0.21$ & $0.17 \pm 0.07$ & $0.33 \pm 0.4$ & $0.18 \pm 0.01$ & $0.22 \pm 0.02$ & $0.49 \pm 0.05$ \\
\hline & 6.3 & -0.65 & -0.5 & 0.1 & 0.00 & -0.02 & -0.07 \\
\hline \multirow[t]{2}{*}{$1.0 \mathrm{E}+05$} & $1.7+\mathrm{E} 05 \pm 8.0+\mathrm{E} 04$ & $1.25 \pm 0.17$ & $0.31 \pm 0.12$ & $0.04 \pm 0.01$ & $0.23 \pm 0.04$ & $0.26 \pm 0.04$ & $0.66 \pm 0.08$ \\
\hline & 11.7 & 2.68 & 0.47 & -0.70 & 0.24 & 0.25 & 0.26 \\
\hline \multirow[t]{2}{*}{ Control } & $4.0+E 00 \pm 1.01+E 00$ & $0.26 \pm 0.03$ & $0.98 \pm 0.02$ & $0.09 \pm 0.01$ & $0.19 \pm 0.00$ & $0.25 \pm 0.00$ & $0.70 \pm 0.03$ \\
\hline & -0.2 & -0.02 & 0.02 & 0.02 & 0.02 & 0.01 & -0.02 \\
\hline
\end{tabular}

Top number=average \pm standard deviation

Bottom number=dimensionless normalized value, where positive and negative values indicate the magnitude of the increase or decrease in the response of the sensor from background level

Table 1: Sensor values for Bacillus thuringiensis spores in DI water.

\begin{tabular}{|c|c|c|c|c|c|c|c|}
\hline $\begin{array}{l}\text { Final Concentration } \\
\text { (spores } / \mathrm{ml} \text { ) }\end{array}$ & $\begin{array}{l}\text { BioSentry } \\
\text { (spores/ml) }\end{array}$ & $\begin{array}{l}\text { HACH Turbidity } \\
\text { (NTU) }\end{array}$ & $\begin{array}{l}\text { HACH TOC } \\
\text { (mg/L) }\end{array}$ & $\begin{array}{l}\text { HACH Chlorine } \\
\text { (mg/L) }\end{array}$ & $\begin{array}{l}\text { S::CAN Turbidity } \\
\text { (FTU) eq }\end{array}$ & $\begin{array}{l}\text { S::CAN DOC } \\
(\mathrm{mg} / \mathrm{L}) \mathrm{eq}\end{array}$ & $\begin{array}{l}\text { S::CAN TOC } \\
\text { (mg/L) eq }\end{array}$ \\
\hline \multirow[t]{2}{*}{$1.0 \mathrm{E}+02$} & $1.8+E 03 \pm 1.3+E 02$ & $0.67 \pm 0.35$ & $0.53 \pm 0.05$ & $0.11 \pm 0.10$ & $0.21 \pm 0.04$ & $0.28 \pm 0.04$ & $0.71 \pm 0.11$ \\
\hline & 1.6 & 1.08 & 0.04 & -0.21 & -0.78 & -0.84 & -0.82 \\
\hline \multirow[t]{2}{*}{$1.0 \mathrm{E}+03$} & $3.2+\mathrm{E} 04 \pm 4.1+\mathrm{E} 03$ & $0.53 \pm 0.14$ & $0 . .68 \pm 0.02$ & $0.03 \pm 0.00$ & $0.23 \pm 0.02$ & $0.33 \pm 0.02$ & $1.01 \pm 0.07$ \\
\hline & 1.2 & 2.8 & 0.26 & -0.13 & 0.33 & 0.39 & 0.50 \\
\hline \multirow[t]{2}{*}{$1.0 \mathrm{E}+04$} & $3.7+E 04 \pm 2.5+E 04$ & $1.62 \pm 2.3$ & $0.8 \pm 0.08$ & $0.09 \pm 0.02$ & $0.3 \pm 0.35$ & $0.5 \pm 0.65$ & $0.8 \pm 0.06$ \\
\hline & 2.0 & 0.14 & 0.95 & -0.22 & 0.66 & 1.17 & 0.34 \\
\hline \multirow[t]{2}{*}{$1.0 \mathrm{E}+05$} & $1.5+E 05 \pm 1.1+E 05$ & $0.91 \pm 0.33$ & $0.47 \pm 0.03$ & $0.08 \pm 0.03$ & $0.29 \pm 0.06$ & $0.33 \pm 0.07$ & $0.89 \pm 0.09$ \\
\hline & 5.1 & 2.67 & 0.00 & -0.29 & 0.50 & 0.67 & 0.56 \\
\hline \multirow[t]{2}{*}{ Control } & $4.4+\mathrm{E} 00 \pm 1.6+\mathrm{E} 00$ & $0.26 \pm 0.02$ & $1.03 \pm 0.09$ & $0.09 \pm 0.00$ & $0.19 \pm 0.00$ & $0.25 \pm 0.01$ & $0.73 \pm 0.01$ \\
\hline & 0.2 & 0.01 & 0.00 & 0.01 & 0.00 & 0.00 & 0.00 \\
\hline
\end{tabular}

Top number=average \pm standard deviation

Bottom number=dimensionless normalized value, where positive and negative values indicate the magnitude of the increase or decrease in the response of the sensor from background level

Table 2: Sensor values for Bacillus thuringiensis spores in filtered tap water.

\begin{tabular}{|c|c|c|c|c|c|c|c|}
\hline $\begin{array}{l}\text { Final Concentration } \\
\text { (spores } / \mathrm{ml} \text { ) }\end{array}$ & $\begin{array}{l}\text { BioSentry } \\
\text { (spores/ml) }\end{array}$ & $\begin{array}{l}\text { HACH Turbidity } \\
\text { (NTU) }\end{array}$ & $\begin{array}{l}\text { HACH TOC } \\
(\mathrm{mg} / \mathrm{L})\end{array}$ & $\begin{array}{l}\text { HACH Chlorine } \\
(\mathrm{mg} / \mathrm{L})\end{array}$ & $\begin{array}{l}\text { S::CAN Turbidity } \\
\text { (FTU) eq }\end{array}$ & $\begin{array}{l}\text { S::CAN DOC } \\
\text { (mg/L) eq }\end{array}$ & $\begin{array}{l}\text { S::CAN TOC } \\
(\mathrm{mg} / \mathrm{L}) \text { eq }\end{array}$ \\
\hline \multirow[t]{2}{*}{$1.0 \mathrm{E}+02$} & $2.09+\mathrm{E} 03 \pm 1.0+\mathrm{E} 03$ & $0.03 \pm 0.00$ & IN & $0.06 \pm 0.02$ & IN & $0.64 \pm 0.07$ & $0.65 \pm 0.24$ \\
\hline & 2.0 & 0.1 & & 0.6 & & 0.17 & 3.82 \\
\hline \multirow[t]{2}{*}{$1.0 \mathrm{E}+03$} & $5.15+\mathrm{E} 03 \pm 1.13+\mathrm{E} 03$ & $0.03 \pm 0.00$ & IN & $0.07 \pm 0.02$ & IN & $0.61 \pm 0.05$ & $0.5 \pm 0.13$ \\
\hline & 5.1 & 0.09 & & 1.15 & & 0.11 & 2.65 \\
\hline \multirow[t]{2}{*}{$1.0 \mathrm{E}+04$} & $1.02+E 04 \pm 1.81+E 03$ & $0.075 \pm 0.00$ & IN & $0.04 \pm 0.00$ & IN & $0.72 \pm 0.13$ & $0.88 \pm 0.4$ \\
\hline & 7.2 & 1.6 & & -0.15 & & 0.31 & 5.45 \\
\hline \multirow[t]{2}{*}{$1.0 \mathrm{E}+05$} & $2.14+\mathrm{E} 05 \pm 7.47+\mathrm{E} 03$ & $0.073 \pm 0.00$ & IN & $0.03 \pm 0.00$ & IN & $0.82 \pm 0.17$ & $1.45 \pm 0.1$ \\
\hline & 10.1 & 1.43 & & -0.20 & & 0.5 & 9.66 \\
\hline \multirow[t]{2}{*}{ Control } & $2.98+E 00 \pm 1.08+E 00$ & $0.03 \pm 0.00$ & IN & $0.03 \pm 0.00$ & IN & $0.54 \pm 0.00$ & $0.14 \pm 0.05$ \\
\hline & 0.8 & 0.006 & & 0.04 & & -0.03 & 0.42 \\
\hline
\end{tabular}

IN=measurement invalid

Top number=average \pm standard deviation

Bottom number=dimensionless normalized value, where positive and negative values indicate the magnitude of the increase or decrease in the response of the sensor from background level

Table 3: Sensor values for Bacillus thuringiensis spores in unfiltered tap water.

$10^{5}$ spores $/ \mathrm{ml}$. This difference is most likely due to the sensor becoming saturated at this higher concentration. However, the BioSentry spore count was significantly higher than the means of cultural, and Petroff Hausser measurements for $B$. thuringiensis at $10^{2}$ and $10^{3}$ spores $/ \mathrm{ml}$ in DI and in unfiltered or filtered tap water $(\mathrm{p}<0.05)$ perhaps due to the presence of small particulates in the water. Overall, BioSentry counts correlated very well with the known injected concentrations for most of the trials. To determine how the BioSentry reacts to mixture of spores in the presence of vegetative bacterial cells, $1.1 \times 10^{6} \mathrm{cfu} / \mathrm{ml}$ of $E$. coli and $8.4 \times 10^{5}$ spores $/ \mathrm{ml}$ of $B$. thuringiensis were jointly added to $45 \mathrm{~L}$ of DI water and passed through the sensors. The BioSentry response was significantly higher for $E$. coli vegetative cells compared to $B$. thuringiensis spores $(\mathrm{p}<0.05$, Figure 5$)$. Interestingly, unknown counts from the BioSentry sensor were also higher than vegetative cells or spore counts. In addition, both $E$. coli and spore BioSentry counts were 2-3 orders of magnitude lower than what was actually added. These data suggest that BioSentry had difficulty distinguishing the mixture of cells and spores, and therefore classified more of them into the unknown category. Our results agree with Miles et al. [5] who investigated the effects of turbidity to determine whether the BioSentry could 


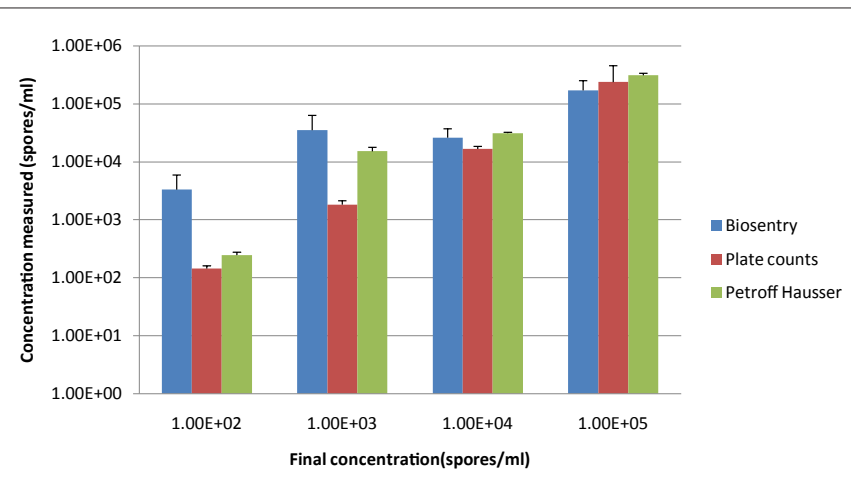

Figure 2: Comparison between cultural, direct and BioSentry counts in response to $B$. thuringiensis spores in DI water.

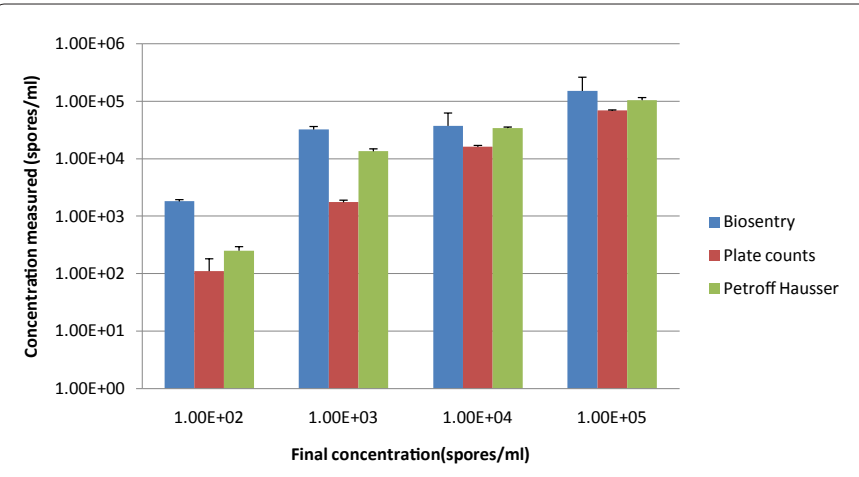

Figure 3: Comparison between cultural, direct and BioSentry counts in response to $B$. thuringiensis spores in filtered tap water.

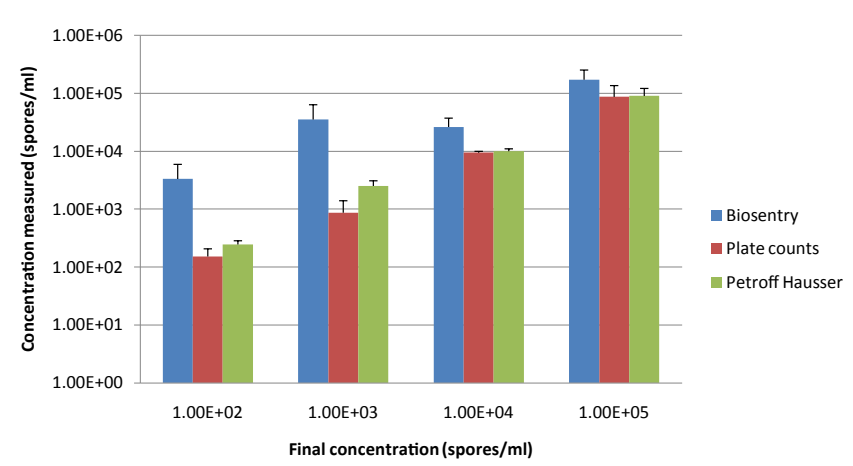

Figure 4: Comparison between cultural, direct and BioSentry counts in response to $B$. thuringiensis spores in unfiltered tap water.

differentiate turbidity causing colloidal particles from microorganisms, and found that the sensor could not distinguish between particulates and

\section{E. coli vegetative cells.}

Other comparisons can be made between different sensor outputs for Total Organic Carbon (TOC) following the addition of spores to DI and filtered tap water. Multiple TOC and DOC measurements are provided by the real-time data acquired from the $\mathrm{HACH}$ and the $\mathrm{S}: \mathrm{CAN}$ sensors. Each of the two TOC sensors uses a different technology for measuring TOC, which perhaps explains why the output received from each TOC sensor was significantly different $(p<0.05)$ even though the concentration of the B. thuringiensis injected was the same (Tables 1-2).

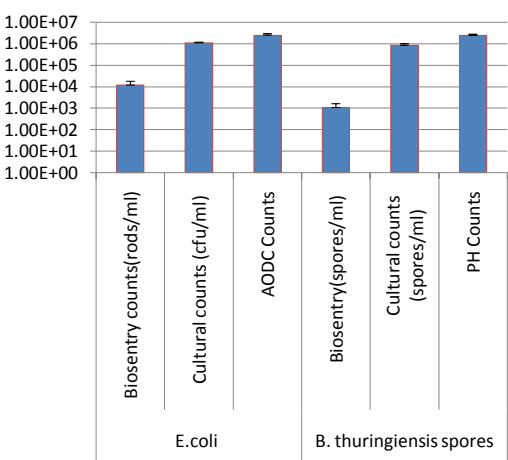

( ${ }^{*} \mathrm{AODC}=$ Acridine Orange Direct Counts, $\mathrm{PH}=$ Petroff Hausser $)$

Figure 5: BioSentry response following exposure to $E$. coli vegetative cells and $B$. thuringiensis spores jointly added together.

One exception to this was for the one concentration of 104 spores $/ \mathrm{ml}$ in filtered tap water, where the TOC concentrations resulting from both sensors were similar. Overall, the responses from these sensors fluctuated as the B. thuringiensis concentration increased (Tables 1-3). Moreover, most parameters decreased with an increase in $B$. thuringiensis concentration. These results agree with previous research which has shown that washed and unwashed B. globigii spores will have different effects on water quality parameters such as free chlorine and turbidity [6] (USEPA, 2009). According to these EPA results, normalized, signal-to-noise corrected sensor parameter response for turbidity in a single pass mode distribution system to unwashed B. globigii spores was 2.4 whereas for washed B. globigii spores was -0.1 . This indicates that biological suspensions if injected with the culture media in which they were cultured, will affect the response of water quality sensors. However, for washed B. thuringiensis spores, there would be no additional TOC inputs; hence, these sensors would not respond. On the other hand, some of these parameters did not respond to injections of $B$. thuringiensis suspension, it should be noted that the manufacturers might not have designed them for detection of low density biological suspensions.

Several studies have also shown that Bacillus spores can be detected using biosensors. Campbell and Mutharasan [7] showed that the Piezoelectric Excited Millimeter-Sized Cantilever (PEMC) sensors can be used to detect Bacillus anthracis spores in real time. Their results suggest that the antibody-functionalized sensor was highly selective to the targeted pathogen. The PEMC sensor is a viable practical sensor for B. anthracis spores in liquid medium, and in presence of Bacillus thuringiensis spores. Zhang et al. [8] developed a biosensor that utilized an anti-Bacillus anthracis monoclonal antibody designated to a mAb $8 \mathrm{G} 3$ functionalized Quartz Crystal Microbalance (QCM). They also indicated that the sensor yielded a distinct response to $B$. anthracis spores and vegetative cells with a detection limit of $10^{3} \mathrm{cfu} /$ $\mathrm{ml}$. Wan et al. [9] demonstrated that phage-based, magneto elastic, wireless biosensors can be used to detect $B$. anthracis Sterne strain spores with greater binding affinity and longevity than antibody based biosensors. Recently, there is increased interest in using aptasensors for the detection of Bacillus spores [10]. Ikanovic et al. [11] developed Aptamer-functionalized Quantum Dots (QDs) to detect Bacillus thuringiensis spores with a detection limit of $10^{3}$ spores $/ \mathrm{ml}$. However, despite the development of a number of laboratory based sensors for the detection of Bacillus spores, it is uncommon for these devices to operate in an on-line or real-time mode within water samples.

To date there are a limited number of studies that have evaluated 
Citation: Sherchan SP, Gerba CP, Pepper IL (2013) Evaluation of Real-Time Water Quality Sensors for the Detection of Intentional Bacterial Spore Contamination of Potable Water. J Biosens Bioelectron 4: 141. doi:10.4172/2155-6210.1000141

Page 5 of 5

the use of commercial water quality sensors for real-time monitoring in distribution systems $[4,5,10,12-14]$. These studies that evaluated commercial sensors in a distribution system show that the magnitude of the response depended on the sensor's ability to detect the contaminant, and the concentration of the contaminate itself. Nevertheless, these studies show that there is potential for using such commerciallyavailable sensors to monitor water in a distribution system. However, only a few published studies demonstrate how sensors respond to microbial contaminants in real-time, which highlights the challenge for the detection of microbial intrusion events. The great majority of commercial sensors measure chemical parameters within drinking water; but in contrast, there are only a few available sensors that allow for the detection of microorganisms in real time [5,15].

This study was successful in evaluating water quality sensors when $B$. thuringiensis was introduced into water within a distribution system. It should be noted that most of the sensors during this study did not respond to spore concentrations $<10$ spores/ml because this concentration could not be distinguished from the background particulates and indigenous organisms in the water. A study conducted by USEPA, evaluated different water quality sensors, and found that multiple angle light scattering device (JMAR BioSentry ${ }^{\circledR}$ ) performed best for the microbial detection of $E$. coli and B. globigii spores. Their level of sensitivity was also $<1 \times 10^{2}$ spores/ml [4]. In addition most sensors problems are related to flow and reagent issues. Reagent flow blockage could lead to the instrument failure and unstable readings. Therefore, it is critical to schedule weekly maintenance and maintain calibration standards in order to ensure everything is operating normally.

\section{Conclusion}

The data from this study evaluated the sensitivity and threshold levels for several in-line sensors that detect microbial intrusions in real-time. The BioSentry sensor successfully detected $B$. thuringiensis spores in real time with a detection limit of $10^{2}$ spores $/ \mathrm{ml}$. Other in-line sensors utilized were incapable of such real-time detection. Overall, data suggest that the BioSentry could be utilized as part of a contaminant warning Supervisory Control and Data System (SCADA), for monitoring intrusion events in water distribution systems.

\section{Acknowledgement}

This work was supported by the University of Arizona National Science Foundation Water and Environmental Technology Center.

\section{References}

1. Helbling DE, Vanbriesen JM (2008) Continuous monitoring of residual chlorine concentrations in response to controlled microbial intrusions in a laboratoryscale distribution system. Water Res 42: 3162-3172.

2. NRC (National Research Council) (2007) Improving the Nation's Water Security: Opportunities for Research. National Academies Press, Washington DC, USA.

3. Greenberg DL, Wagner DM (2007) Standard Operating Procedure for the Purification of Bacillus sp. Spores for the Assessment of Surrogates to Bacillus anthracis. Microbial Genetics and Genomics Center, Northern Arizona University, Flagstaff, AZ, USA.

4. USEPA (2010) Detection of biological suspensions using online detectors in a drinking water distributions system simulator, EPA/600/R-10/005,Washington DC, USA.

5. Miles SL, Sinclair RG, Riley MR, Pepper IL (2011) Evaluation of select sensors for real-time monitoring of Escherichia coli in water distribution systems. App Environ Microbiol 77: 2813-2816.

6. USEPA (2009) Distribution System Water Quality Monitoring: Senso Technology Evaluation Methodology and Results, EPA 600/R-09/076, Washington DC, USA.

7. Campbell GA, Mutharasan R (2006) Piezoelectric-excited millimeter-sized cantilever (PEMC) sensors detect Bacillus anthracis at 300 spores $/ \mathrm{mL}$. Biosens Bioelectron 21: 1684-1692.

8. Zhang X, Hao R, Wang D, Zuo G, Wei H, et al. (2009) Rapid detection of Bacillus anthracis using monoclonal antibody functionalized QCM sensor. Biosens Bioelectron 24: 1330-1335.

9. Wan J, Huihua S, Shichu H, Fiebor B, IH Chen, et al. (2007) Phage-Based Magneto elastic Wireless Biosensors for Detecting Bacillus anthracis Spores, IEEE Sens J, 7: 470-477.

10. Bruno JG, Carrillo MP (2012) Development of aptamer beacons for rapid presumptive detection of Bacillus spores. J Fluoresc 22: 915-924.

11. Ikanovic M, Rudzinski WE, Bruno JG, Allman A, Carrillo MP, et al. (2007) Fluorescence assay based on aptamer-quantum dot binding to Bacillus thuringiensis spores. J Fluoresc 17: 193-199.

12. Hall JS, Zaffiro AD, Marx RB, Kefauver PC, Krishnan ER et al. (2007) On-line water quality parameters as indicators of distribution system contamination. $J$ AWWA, 99: 66-77.

13. Allmann TP, Carlson KH (2005) Modeling intentional distribution system contamination and detection. J.AWWA, 97: 58-71.

14. Byer D, Carlson KH (2005) Real-time detection of intentional chemical contamination in the distribution system. Journal AWWA, 97: 130-133.

15. USEPA (2006) Water Quality Sensor Responses to Potential Chemical Threats in a Pilot-scale Water Distribution System, EPA/600/R-06/068, Washington DC USA. 